\section{(6) \\ OPEN ACCESS}

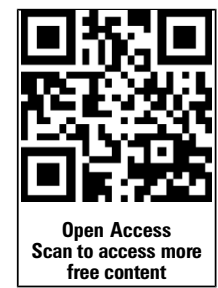

Handling editor Tore K Kvien

- Additional material is published online only. To view please visit the journal online (http://dx.doi.org/10.1136/ annrheumdis-2015-208742).

${ }^{1}$ Rheumatology Department Cavale Blanche Hospital and Brest Occidentale University,

Brest, France

2EA 2216, ERI 29, Brest

University, Brest, France

${ }^{3}$ Rheumatology Department,

Hôtel Dieu University Hospital,

Nantes, France

${ }^{4}$ Nuclear Medicine Department, Morvan University Hospital, Brest, France

${ }^{5}$ Radiology Department, Cavale Blanche Hospital and Brest Occidentale University, Brest France

${ }^{6}$ Rheumatology Department, Fort de France, Martinique, France

${ }^{7}$ Clinical Investigation Centre [CIC] 1412, Institut National de la Santé et de la Recherche Médicale[INSERM], Brest, France

\section{Correspondence to} Professor Valerie Devauchelle, Rheumatology Unit, Hôpital de la Cavale Blanche, BP 824, Brest cedex F 29609, France; valerie.devauchelle-pensec@ chu-brest.fr

Received 8 October 2015 Revised 6 January 2016 Accepted 22 January 2016 Published Online First 29 February 2016

\title{
Efficacy of first-line tocilizumab therapy in early polymyalgia rheumatica: a prospective longitudinal study
}

\author{
Valérie Devauchelle-Pensec, ${ }_{1}^{1,2}$ Jean Marie Berthelot, ${ }^{3}$ Divi Cornec, ${ }_{1}^{1,2}$ \\ Yves Renaudineau, ${ }^{2}$ Thierry Marhadour, ${ }^{1}$ Sandrine Jousse-Joulin, ${ }^{1,2}$ Solène Querellou, ${ }^{4}$ \\ Florent Garrigues, ${ }^{5}$ Michel De Bandt, ${ }^{6}$ Maelenn Gouillou, ${ }^{7}$ Alain Saraux ${ }^{1,2}$
}

\section{ABSTRACT}

Background Glucocorticoids are the cornerstone treatment of polymyalgia rheumatica (PMR) but induce adverse events.

Objectives To evaluate the efficacy and safety of firstline tocilizumab in PMR.

Methods In a prospective open-label study (ClinicalTrials.gov: NCT01713842), 20 glucocorticoid-free patients fulfilling Chuang's PMR criteria, with symptom onset within the last 12 months and a PMR activity score $(P M R-A S)>10$, each received three tocilizumab infusions at 4-week intervals, without glucocorticoids, followed by oral prednisone from weeks 12 to 24 $(0.15 \mathrm{mg} / \mathrm{kg}$ if PMR-AS $\leq 10$ and $0.30 \mathrm{mg} / \mathrm{kg}$ otherwise). The primary end point was the proportion of patients with PMR-AS $\leq 10$ at week 12 .

Results Baseline median PMR-AS was 36.6 (IQR 30.443.8). At week 12, all patients had PMR-AS $\leq 10$ and received the low prednisone dosage. Median PMR-AS at weeks 12 and 24 was 4.5 (3.2-6.8) and 0.95 (IQR $0.4-2)$, respectively $(p<0.001$ vs baseline for both time points). No patient required rescue treatment. Positron emission tomography-CT showed significant improvements. The most common adverse events were transient neutropenia $(n=3)$ and leucopenia $(n=5)$; in one patient, the second tocilizumab infusion was omitted due to leucopenia.

Conclusions Tocilizumab monotherapy is effective in recent-onset PMR. Randomised controlled trials are warranted.

Trial registration number NCT01713842.

\section{INTRODUCTION}

Glucocorticoids are the therapeutic mainstay in polymyalgia rheumatica (PMR). ${ }^{1}{ }^{2}$ However, their adverse effects (ie, osteoporosis, diabetes and hypertension) are of particular concern in elderly patients. $^{3} 4$ Among other tested drugs, ${ }^{5}{ }^{6}$ only methotrexate $^{7}$ was effective. Tocilizumab is a humanised antibody to the soluble interleukin- 6 receptor that may be effective in PMR. ${ }^{8-10}$

The PMR activity score (PMR-AS) ${ }^{11}$ relies on five variables: morning stiffness (in minutes), elevation of the upper limbs (rated 0-3), physician's global assessment and pain intensity on 10-point visual analogue scales (VASs) and $\mathrm{C}$ reactive protein (CRP) level in $\mathrm{mg} / \mathrm{dL}$; the erythrocyte sedimentation rate $(\mathrm{ESR})$ can replace $\mathrm{CRP}^{12} \mathrm{PMR}-\mathrm{AS}<7$ defines low-disease activity and PMR-AS >17 highdisease activity. ${ }^{11}{ }^{12}$ However, for making treatment decisions in everyday practice, PMR-AS $\geq 10$ was the best cut-off ${ }^{13}$ to define a flare ${ }^{14}$ and guide glucocorticoid dosage adjustments. ${ }^{15}$

We performed a 24-week, open-label, longitudinal, prospective study of the safety and efficacy of tocilizumab in recent-onset PMR (Tolerance and Efficacy of Tocilizumab in Polymyalgia Rheumatica study).

\section{PATIENTS AND METHODS}

\section{Study design, setting and participants}

The protocol was registered on Clinicaltrials.gov (NCT01713842). Tocilizumab was given as three intravenous infusions, at baseline then 4 and 8 weeks later, in a dosage of $8 \mathrm{mg} / \mathrm{kg}$. The primary end point was evaluated at week 12 .

From weeks 12 to 24 , patients were to receive prednisone, in a low dosage of $0.15 \mathrm{mg} / \mathrm{kg} / \mathrm{day}$ if their PMR-AS was $\leq 10$ and in the standard dosage of $0.3 \mathrm{mg} / \mathrm{kg} / \mathrm{day}$ otherwise. The PMR-AS was determined every four weeks; if $\leq 10$, the prednisone dosage was decreased by $1 \mathrm{mg}$ every two weeks and if $>10$ the dosage was increased from low to standard or, in patients already on the standard dosage, by $5 \mathrm{mg}$ (figure $\mathrm{S} 1$ shows the study design).

\section{Setting and participants}

Patients were recruited at two university hospitals in France. Inclusion criteria were PMR meeting Chuang's criteria, ${ }^{16}$ with onset within the past 12 months, active disease defined as PMR-AS $>10$ and either no history of glucocorticoid therapy for PMR or glucocorticoid therapy for no longer than 1 month stopped at least 7 days before inclusion; informed consent to the study; age 50-80 years; any non-steroidal anti-inflammatory drug (NSAID) therapy stopped at least 2 days before inclusion; $\mathrm{ESR} \geq 40 \mathrm{~mm} / \mathrm{h}$ or $\mathrm{CRP} \geq 10 \mathrm{mg} / \mathrm{dL}$; and no evidence of other inflammatory rheumatic or connective disease. Exclusion criteria were clinical symptoms suggesting giant-cell arteritis; immunosuppressive therapy; uncontrolled dyslipidaemia or cardiovascular disease; chronic infection; evidence of hydroxyapatite crystal disease or chondrocalcinosis or severe osteoarthritis of the hip and/or shoulder; symmetrical peripheral arthritis; active thyroid disease and drug-related myalgia. ${ }^{17}$ 


\section{Data collection}

At each visit, the patients completed three $100 \mathrm{~mm}$ VASs, for fatigue, global disease activity and pain; and the short form 36 (SF36) quality-of-life questionnaire. The absence of giant-cell arteritis was checked.

B-mode ultrasonography, MRI of the shoulders and pelvic girdles and ${ }^{18}$ fluorodeoxyglucose positron emission tomography/CT (PET-CT) were performed at baseline then 2 and 12 weeks later.

\section{Outcomes and follow-up}

The prespecified primary end point was the proportion of patients whose PMR-AS was $\leq 10$ at week 12. Secondary end points included the PMR-AS response and the PMR-AS (ESR) response (used to eliminate bias due to the direct effect of tocilizumab on CRP), at weeks 2, 4, 8, 12, 16, 20 and 24. Changes in shoulder and hips-girdle imaging findings from baseline to weeks 2 and 12 were evaluated using semi-quantitative scores. We assessed changes from baseline to each evaluation time point in VAS scores, SF36 scores, CRP level and ESR.

Adverse events were recorded at each visit from baseline to week 24 according to the Medical Dictionary for Regulatory Activities. Data were collected until the end of prednisone therapy; clinical events, time to prednisone discontinuation and median prednisone dose were recorded.

\section{Statistical analysis}

We estimated the required sample size based on the CI of the proportion of patients in remission (PMR-AS $\leq 10)$ at week 12 . Including 20 patients and assuming a 75\% (15/20) remission rate would produce a CI of 50.6-90.4, indicating a $>50 \%$ true remission rate.

We described continuous variables as median and IQR and categorical variables as $\mathrm{n}(\%)$. To compare values between two time points, we chose the Wilcoxon signed-rank test for paired data and the McNemar test for categorical data.

The potential glucocorticoid-sparing effect of tocilizumab was assessed by comparing the prednisone dosage at week 24 to the cumulative prednisone dosage indicated by the British Society for Rheumatology (BSR) recommendations ${ }^{1}(0.30 \mathrm{mg} / \mathrm{kg} /$ day for 3 weeks then taper in the absence of giant-cell arteritis symptoms to $12.5 \mathrm{mg} /$ day for 3 weeks then $10 \mathrm{mg} /$ day for $4-$ 6 weeks then $1 \mathrm{mg}$ decrease every six weeks). We performed a sensitivity analysis using the initial dosage and taper recommended by the $\mathrm{BSR},{ }^{1}$ that is, $15 \mathrm{mg} /$ day irrespective of body weight.

We used SAS, V.9.3 (SAS Institute, Cary, North Carolina, USA) for all analyses.

\section{RESULTS}

\section{Patient characteristics}

The analysis included 20 patients who received at least one tocilizumab infusion (see online supplementary figure S2), 13 males and 7 females, with a median age of 66.9 years $(62.0-72.5)$ and a median disease duration of 99 days (67-163). Median baseline PMR-AS was 36.65 (30.45-43.85); 18 (90\%) patients had shoulder and pelvic girdle pain with morning stiffness for a median of $180.0(75.0-180.0)$ min. Systemic manifestations were fever ( $2 / 20$ patients), $>5 \%$ weight loss $(3 / 20)$ and serum gamma-glutamyl transpeptidase elevation (9/20 patients). No patient had rheumatoid factors or peripheral arthritis.

Of the 20 patients, 19 met Chuang's criteria and 1 had a low ESR but elevated CRP $(>40 \mathrm{mg} / \mathrm{dL})$. Provisional American College of Rheumatology (ACR)/European League Against
Rheumatism (EULAR) criteria were met by 18 (90\%) patients, whereas 2 had no bilateral shoulder aching at inclusion. The global score without ultrasound was 6 in each of the 17 patients and 5 in 1 patient. With ultrasound, 15 (75\%) had bilateral shoulder bursitis and all 20 had a score $\geq 6{ }^{18}$

All 20 patients had recent-onset disease, with a symptom duration $<5$ months in 15 patients (median 99 days; 25th-75th percentiles, 67-163). At inclusion, 7/20 (35\%) patients had taken glucocorticoid therapy, always for $<1$ month and with discontinuation at least 7 days before inclusion; 9/20 (45\%) had taken NSAIDs.

\section{Efficacy}

Tocilizumab efficacy was evaluated at weeks 4,8 and 12. All patients achieved the primary end point of PMR-AS $\leq 10$ by week 12 (table 1). Median PMR-AS was 36.6 (30.4-43.8) at baseline and $4.50(3.2-6.8)$ at week $12(\mathrm{p}<0.001)$. By week 2 , there was already a significant improvement (median 19.75 (14.9-27.7)) (figure 1); PMR-AS was $\leq 10$ in $3(15 \%)$ patients at week 2, $9(45 \%)$ at week 4 and $13(65 \%)$ at week 8. Very low disease activity (PMR-AS $<7)^{11}$ was noted in $1(5 \%)$ patient at week 2, $4(20 \%)$ at week 4, $12(60 \%)$ at week 8 and $17(85 \%)$ at week 12. PMR-AS (ESR) values also improved.

No patient required rescue treatment during the first 12 study weeks. All patients were started on low-dose prednisone $(0.15 \mathrm{mg} / \mathrm{kg} /$ day $)$ at week 12 ; median starting dosage was $12 \mathrm{mg}$ (9.0-12.5). At weeks 16, 20 and 24, the prednisone dosage was decreased according to the study protocol. Median PMR-AS improved significantly from weeks 12 to 24 (from 4.50 (3.2$6.8)$ to $0.95(0.4-2.0))$. No patient required rescue therapy or had a flare during the prednisone phase.

The median cumulative dose predicted by BSR recommendations, ${ }^{1}$ with an initial dosage of $0.3 \mathrm{mg} / \mathrm{kg} /$ day, was $2705.3 \mathrm{mg}$ (2158.8-2848.4), which was significantly higher than the median cumulative dose in our patients $(808.5 \mathrm{mg}$ (673.3$866.3))(\mathrm{p}<0.001)$ at week 24 (see online supplementary table $\mathrm{S} 1)$. The glucocorticoid-sparing effect of tocilizumab was $70.2 \%$.

Follow-up was provided 1 year after the end of prednisone therapy, for a median of 12 (12-17) months after week 24 in 18 patients; two patients were lost to follow-up. Six months after week 24 , only four patients were still on prednisone therapy and median daily prednisone dosage was 0 . At the end of the follow-up, median cumulative prednisone dose was $560 \mathrm{mg}$ (405-755.25). No patient had flares or giant-cell arteritis. One patient experienced a moderate relapse 2 months after prednisone discontinuation; she had received only two tocilizumab infusions, due to an adverse event, and she achieved a second remission after 4 weeks of prednisone therapy, $5 \mathrm{mg} /$ day.

Table 1 reports the other secondary efficacy outcomes. CRP returned to normal within 2 weeks of tocilizumab initiation. All VAS scores decreased, and the decreases were largest for pain and disease activity. Both the physical and the mental components of the SF36 improved. No patient developed symptoms of giant-cell arteritis during follow-up.

Major improvements were noted in clinical and laboratory variables and in the PMR-AS, contrasting with only moderate improvements by PET-CT or MRI and no improvements by ultrasonography (table 2).

\section{Safety}

Online supplementary table S2 reports the adverse events, serious adverse events and discontinuations due to adverse events. No cases of opportunistic infection, tuberculosis or 
Table 1 Global treatment efficacy during the tocilizumab and prednisone periods

\begin{tabular}{|c|c|c|c|c|c|c|c|c|c|c|}
\hline Median, IQR & Week 0 & Week 2 & Week 4 & Week 8 & Week 12 & $\begin{array}{l}p \text { Value } \\
\text { Week } 0 \text { vs } \\
\text { week } 12\end{array}$ & Week 16 & Week 20 & Week 24 & $\begin{array}{l}p \text { Value } \\
\text { Week } 12 \text { vs } \\
\text { week } 24\end{array}$ \\
\hline PMR-AS & $36.6(30.4-43.8)$ & $19.7(14.9-27.7)$ & $11.0(7.9-19.3)$ & $5.8(3.7-11.6)$ & $4.5(3.2-6.8)$ & $<0.001^{*}$ & $1.4(0.9-3.2)$ & $1.5(0.5-2.4)$ & $0.9(0.4-2.0)$ & $<0.001^{*}$ \\
\hline $\mathrm{CRP}, \mathrm{mg} / \mathrm{dL}$ & $65.1(21.6-127.8)$ & $0.5(0.3-1.4)$ & $0.6(0.3-3.5)$ & $0.6(0.2-1.2)$ & $0.2(0.1-1.0)$ & $<0.001^{*}$ & $1.5(0.9-4.6)$ & $2.5(0.2-6.3)$ & $2.3(0.9-6.5)$ & $0.004^{*}$ \\
\hline $\mathrm{ESR}, \mathrm{mm} / \mathrm{h}$ & $51.0(34.0-79.5)$ & $7.5(4.0-9.5)$ & $5.0(4.0-10.0)$ & $4.5(2.0-5.0$ & $2.00(2.0-4.5)$ & $<0.001^{*}$ & $4.5(3.0-10.5)$ & $5.0(3.0-14.5)$ & $7.0(3.5-12.0)$ & $0.001^{*}$ \\
\hline Patient VAS for pain & $6.4(4.6-7.8)$ & $5.4(3.8-6.9)$ & $4.5(3.2-5.4)$ & $2.2(1.5-4.2)$ & $1.7(0.6-2.7)$ & $<0.001^{*}$ & $0.6(0.1-1.7)$ & $0.4(0.2-1.3)$ & $0.1(0.1-0.7)$ & $0.001 *$ \\
\hline Patient VAS for fatigue & $5.4(2.9-6.9)$ & $5.3(3.0-6.2)$ & $4.5(2.0-5.1)$ & $2.8(1.0-4.8)$ & $2.1(0.7-4.4)$ & $<0.001^{*}$ & $0.8(0.3-1.9)$ & $0.4(0.2-2.2)$ & $0.2(0.1-1.0)$ & $<0.001^{*}$ \\
\hline Patient VAS for disease activity & $6.6(4.8-7.5)$ & $5.45(3.8-6.9)$ & $4.5(3.1-5.4)$ & $2.2(1.5-4.2)$ & $2.0(0.9-3.6)$ & $<0.001^{*}$ & $0.6(0.1-1.7)$ & $0.4(0.2-1.3)$ & $0.2(0.1-1.2)$ & $<0.001^{*}$ \\
\hline Physician VAS for disease activity & $6.8(6.0-7.9)$ & $4.4(2.8-6.6)$ & $2.7(1.7-4.5)$ & $2.1(0.5-3.1)$ & $1.1(0.8-1.8)$ & $<0.001^{*}$ & $0.3(0.0-0.8)$ & $0.1(0.0-0.2)$ & $0.0(0.0-0.2)$ & $0.001^{*}$ \\
\hline MST (min) & $180.0(75.0-180.0)$ & $60.0(60.0-120.0)$ & $30.0(7.50-60.0)$ & $5.0(0.0-22.5)$ & $4.0(0.0-10.0)$ & $<0.001^{*}$ & $0.0(0.0-1.5)$ & $0.0(0.0-0.0)$ & $0.0(0.0-0.5)$ & $0.012^{*}$ \\
\hline EUL & $0.5(0.0-2.0)$ & $0.0(0.0-2.0)$ & $0.0(0.0-1.0)$ & $0.0(0.0-0.0)$ & $0.0(0.0-0.0)$ & $0.002^{*}$ & $0.0(0.0-0.0)$ & $0.0(0.0-0.0)$ & $0.0(0.0-0.0)$ & $0.500^{*}$ \\
\hline 0 & $10(50.0 \%)$ & $11(55.0 \%)$ & $13(65.0 \%)$ & $17(85.0 \%)$ & $18(90.0 \%)$ & & $20(100 \%)$ & $20(100 \%)$ & $20(100.0 \%)$ & \\
\hline 1 & $2(10.0 \%)$ & $3(15.0 \%)$ & $4(20.0 \%)$ & $2(10.0 \%)$ & $2(10.0 \%)$ & & $0(0.0 \%)$ & $0(0.0 \%)$ & $0(0.0 \%)$ & \\
\hline 2 & $8(40.0 \%)$ & $6(30.0 \%)$ & $3(15.0 \%)$ & $1(5.0 \%)$ & $0(0.0 \%)$ & & $0(0.0 \%)$ & $0(0.0 \%)$ & $0(0.0 \%)$ & \\
\hline 3 & $0(0.0 \%)$ & $0(0.0 \%)$ & $0(0.0 \%)$ & $0(0.0 \%)$ & $0(0.0 \%)$ & & $0(0.0 \%)$ & $0(0.0 \%)$ & $0(0.0 \%)$ & \\
\hline PMR-AS (ESR) & $35.6(30.4-39.9)$ & $20.8(15.3-29.4)$ & $13.7(9.3-22.0)$ & $5.8(3.5-11.8)$ & $4.7(3.5-6.6)$ & $<0.001^{*}$ & $1.9(1.3-3.6)$ & $1.9(0.7-2.9)$ & $1.5(0.7-2.9)$ & $<0.001^{*}$ \\
\hline \multicolumn{11}{|l|}{ SF-36 } \\
\hline MCS & $39.6(35.4-50.7)$ & $40.8(35.7-51.0)$ & $45.0(35.7-53.0)$ & $42.8(38.2-55.6)$ & $47.7(38.5-56.1)$ & $0.058^{*}$ & $52.1(45.3-56.1)$ & $52.9(46.2-55.6)$ & $53.1(48.0-55.2)$ & $0.055^{*}$ \\
\hline PCS & $27.2(22.4-32.6)$ & $30.3(27.4-35.0)$ & $34.3(28.8-36.8)$ & $35.5(32.6-43.1)$ & $40.6(34.7-50.1)$ & $<0.001^{*}$ & $50.8(43.7-53.8)$ & $48.2(46.0-54.7)$ & $48.7(42.6-53.6)$ & $0.016^{*}$ \\
\hline
\end{tabular}

* $\mathrm{p}$ Value was calculated using the Wilcoxon signed-rank test for paired data and the McNemar test for categorical variables.

CRP, C reactive protein; ESR, erythrocyte sedimentation rate; EUL, 0-3 scale for elevation of the upper limbs; MCS, mental component summary of the SF36; MST, morning stiffness; PCS, physical component summary of the SF36; PMR-AS, polymyalgia rheumatica activity score; SF36, short-form 36 quality-of-life questionnaire; VAS, 0-10 visual analogue scale. 

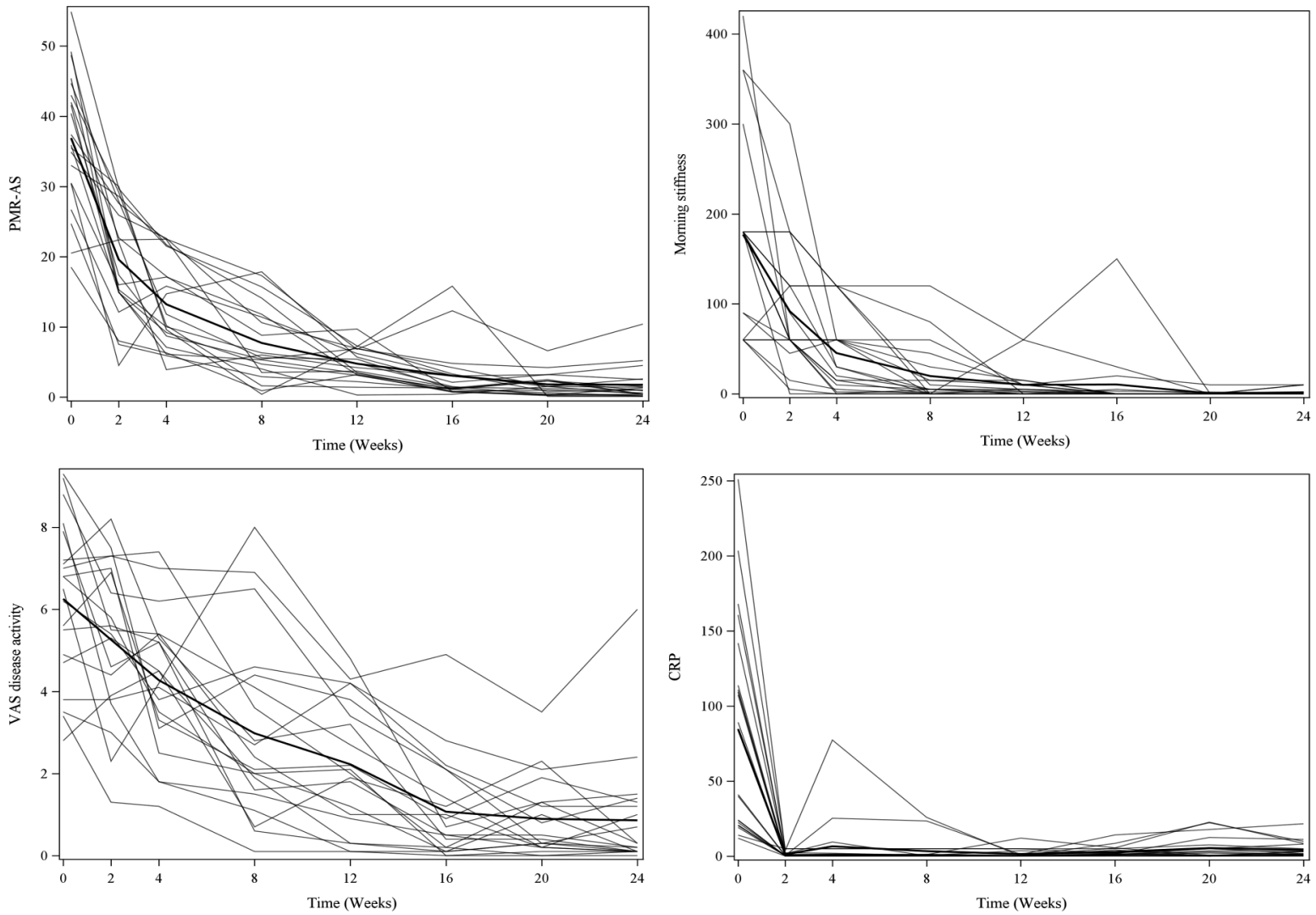

Figure 1 Efficacy of tocilizumab and prednisone on the polymyalgia rheumatica activity score (PMR-AS) and three of its components. CRP, C reactive protein; VAS, visual analogue scale.

death were recorded. Cancer unrelated to PMR was diagnosed in two patients. Of the 37 adverse events recorded in 14 patients during tocilizumab therapy, 22 were ascribed to tocilizumab. The most common tocilizumab-related adverse events were leucopenia (five instances in three patients) and neutropenia (seven instances in five patients). Leucopenia

Table 2 Findings from imaging studies at baseline and 2 and 12 weeks after tocilizumab initiation

\begin{tabular}{|c|c|c|c|c|c|c|}
\hline & Week 0 & Week 2 & Week 12 & $\begin{array}{l}\text { p Value } \\
\text { (week } 0 \text { vs week 2) }\end{array}$ & $\begin{array}{l}\text { p Value } \\
\text { (week } 12 \text { vs week } 0 \text { ) }\end{array}$ & $\begin{array}{l}\text { p Value } \\
\text { (week } 12 \text { vs week 2) }\end{array}$ \\
\hline $\begin{array}{l}\text { PET-CT } \\
\text { SUV max (hips) }\end{array}$ & $\begin{array}{l}n=19 \\
6.35(5.35-7.45)\end{array}$ & $\begin{array}{l}n=15 \\
5.30(4.50-6.85)\end{array}$ & $\begin{array}{l}n=16 \\
4.85(4.23-5.53)\end{array}$ & 0.007 & $<0.001$ & 0.017 \\
\hline $\begin{array}{l}\text { PET-CT } \\
\text { SUV max (shoulders) }\end{array}$ & $\begin{array}{l}n=18 \\
5.80(4.95-6.50)\end{array}$ & $\begin{array}{l}n=14 \\
5.48(4.95-6.00)\end{array}$ & $\begin{array}{l}n=16 \\
4.95(4.35-5.90)\end{array}$ & 0.178 & 0.081 & 0.265 \\
\hline $\begin{array}{l}\text { US B mode } \\
\text { (shoulders) } \\
0-1 \\
>1\end{array}$ & $\begin{array}{l}n=19 \\
1.00(0.50-1.50) \\
12(63.2 \%) \\
7(36.8 \%)\end{array}$ & $\begin{array}{l}n=19 \\
1.00(0.00-1.00) \\
15(79.0 \%) \\
4(21.0 \%)\end{array}$ & $\begin{array}{l}n=19 \\
0.50(0.00-1.00) \\
16(84.2 \%) \\
3(15.8 \%)\end{array}$ & $\begin{array}{l}0.272 \\
0.508\end{array}$ & $\begin{array}{l}0.148 \\
0.289\end{array}$ & $\begin{array}{l}0.180 \\
1.000\end{array}$ \\
\hline $\begin{array}{l}\text { US B mode } \\
\text { (hips) } \\
0-1 \\
>1\end{array}$ & $\begin{array}{l}\mathrm{n}=19 \\
0.00(0.00-0.00) \\
19(100.0 \%) \\
0(0.0 \%)\end{array}$ & $\begin{array}{l}\mathrm{n}=19 \\
0.00(0.00-0.00) \\
19(100.0 \%) \\
0(0.0 \%)\end{array}$ & $\begin{array}{l}\mathrm{n}=19 \\
0.00(0.00-0.00) \\
19(100.0 \%) \\
0(0.0 \%)\end{array}$ & 0.250 & 0.250 & \\
\hline $\begin{array}{l}\text { MRI } \\
\text { (shoulders) } \\
0-1 \\
>1\end{array}$ & $\begin{array}{l}n=14 \\
1.00(1.00-2.00) \\
8(57.1 \%) \\
6(42.9 \%)\end{array}$ & $\begin{array}{l}n=12 \\
1.00(1.00-1.50) \\
7(58.3 \%) \\
5(41.7 \%)\end{array}$ & $\begin{array}{l}n=16 \\
1.00(1.00-1.50) \\
9(56.3 \%) \\
7(43.7 \%)\end{array}$ & $\begin{array}{l}0.500 \\
1.000\end{array}$ & $\begin{array}{l}0.254 \\
1.000\end{array}$ & $\begin{array}{l}0.172 \\
1.000\end{array}$ \\
\hline $\begin{array}{l}\text { MRI } \\
\text { (hips) } \\
0-1 \\
>1\end{array}$ & $\begin{array}{l}\mathrm{n}=15 \\
1.50(1.50-2.00) \\
2(13.3 \%) \\
13(86.7 \%)\end{array}$ & $\begin{array}{l}n=13 \\
1.00(1.00-1.50) \\
7(53.9 \%) \\
6(46.1 \%)\end{array}$ & $\begin{array}{l}\mathrm{n}=16 \\
1.00(1.00-1.50) \\
11(68.8 \%) \\
5(31.2 \%)\end{array}$ & $\begin{array}{l}0.094 \\
0.031\end{array}$ & $\begin{array}{l}0.005 \\
0.023\end{array}$ & $\begin{array}{l}0.078 \\
0.625\end{array}$ \\
\hline
\end{tabular}

The data are median (IQR) or $\mathrm{n}$ (\%). B-mode ultrasonography (US) was used to evaluate the shoulders (sub-deltoid bursitis) and hips (synovitis and/or trochanteric bursitis). The images were interpreted using a semi-quantitative scale for bursitis and synovial effusion ( 0 , normal; 1 , slight; 2 , moderate; and 3, severe). MRI of the shoulders and pelvic girdle was performed using a 3 T superconductive magnet system (axial T1 without fat suppression) and sagittal and axial T2-short time inversion recovery sequences. The images were interpreted using a semi-quantitative scale for bursa and joint effusion (0, normal; 1 , slight; 2 , moderate; and 3, severe). ${ }^{18}$ Fluorodeoxyglucose positron emission tomography/CT (PET-CT) was performed using a Biograph mCT PET-CT 64 scanner, and the median global standardised uptake values (SUVs) at the shoulders and pelvic girdle were recorded. $\mathrm{p}$ Values were calculated using the Wilcoxon signed-rank test for paired data and the McNemar test for categorical variables; $p<0.05$ was considered significant. 
prompted a tocilizumab dosage decrease to $4 \mathrm{mg} / \mathrm{kg}$ at weeks 4 and 8 in three patients and withholding of the week 4 dose in another patient (see online supplementary figure S2). Three infections were classified as tocilizumab-related but were of moderate severity. Dyslipidaemia occurred on four occasions in three patients but resolved spontaneously. During the prednisone phase, 17 adverse events were reported in 10 patients, including 6 classified as prednisone related. Loss of control of pre-existing diabetes mellitus occurred in one patient. Severe insomnia was reported by two patients, including one in whom this symptom required acceleration of the prednisone taper. Dyslipidaemia occurred in one patient.

\section{DISCUSSION}

In our study, tocilizumab was effective in controlling recent-onset PMR when used alone, without glucocorticoid therapy. All patients achieved the primary end point by week 12 and required only low-dose prednisone after tocilizumab therapy; $85 \%$ of patients achieved very low disease activity (PMR-AS $<7$ ) by week 12 . All secondary end points improved.

The response to tocilizumab seems slow. However, in a recent prospective ACR/EULAR study of 125 patients with PMR, ${ }^{18} 19$ only $71 \%$ of patients had a complete response to glucocorticoid therapy by week 4 .

Four $(20 \%)$ patients required tocilizumab dosage reductions due to leucopenia, but no serious adverse events were recorded. We recommend close monitoring of peripheral leucocyte counts during tocilizumab therapy for PMR. PET-CT showed moderate albeit significant improvements. However, limited data are available on tissue-level effects of tocilizumab in PMR, which probably differ from those seen in rheumatoid arthritis.

Limitations of our study include the non-randomised design, which was, however, appropriate for this proof-of-concept study. The PMR-AS was the only available AS but includes the CRP level, which tocilizumab affects directly. The use of other ASs or primary end points deserves consideration. ${ }^{20}$ Whether tocilizumab is a glucocorticoid-sparing agent in PMR requires confirmation.

Acknowledgements The authors thank the French rheumatologists and general practitioners who referred their patients to the TENOR study. They are grateful to Marie Jezequel and Nathalie Bihannic $(\mathrm{CIC})$ for centralising the material and to Audrey Le Goff-Coquet and Valentine Guiton (DRCI). They also thank the staff for their time and commitment to this work.

Funding Roche-Chugai provided an unconditional grant for the study and donated the tocilizumab

Competing interests None declared.

Patient consent Obtained.

Ethics approval This study was approved by the appropriate ethics committee (CPP Ouest VI)

Provenance and peer review Not commissioned; externally peer reviewed.
Open Access This is an Open Access article distributed in accordance with the Creative Commons Attribution Non Commercial (CC BY-NC 4.0) license, which permits others to distribute, remix, adapt, build upon this work non-commercially, and license their derivative works on different terms, provided the original work is properly cited and the use is non-commercial. See: http://creativecommons.org/ licenses/by-nc/4.0/

\section{REFERENCES}

1 Dasgupta B, Borg FA, Hassan N, et al. BSR and BHPR guidelines for the management of polymyalgia rheumatica. Rheumatology (Oxford) 2010;49:186-90.

2 De Bandt M. Current diagnosis and treatment of polymyalgia rheumatica. Joint Bone Spine 2014;81:203-8.

3 Kremers HM, Reinalda MS, Crowson CS, et al. Direct medical costs of polymyalgia rheumatica. Arthritis Rheum 2005;53:578-84.

4 Naranjo A, López R, García-Magallón B, et al. Longitudinal practice patterns of prophylaxis of glucocorticoid-induced osteoporosis in patients with polymyalgia rheumatica. Rheumatol Int 2014;34:1459-63.

5 Dejaco $C$, Singh YP, Perel $P$, et al. Current evidence for therapeutic interventions and prognostic factors in polymyalgia rheumatica: a systematic literature review informing the 2015 European League Against Rheumatism/American College of Rheumatology recommendations for the management of polymyalgia rheumatica. Ann Rheum Dis 2015;74:1808-17.

6 Dejaco C, Singh YP, Perel P, et al. 2015 Recommendations for the management of polymyalgia rheumatica: a European League Against Rheumatism/American College of Rheumatology collaborative initiative. Ann Rheum Dis 2015;74:1799-807.

7 Caporali R, Cimmino MA, Ferraccioli G, et al. Prednisone plus methotrexate for polymyalgia rheumatica: a randomized, double-blind, placebo-controlled trial. Ann Intern Med 2004;141:493-500.

8 Hagihara K, Kawase I, Tanaka T, et al. Tocilizumab ameliorates clinical symptoms in polymyalgia rheumatica. J Rheumatol 2010;37:1075-6.

9 Izumi $\mathrm{K}$, Kuda $\mathrm{H}$, Ushikubo $\mathrm{M}$, et al. Tocilizumab is effective against polymyalgia rheumatica: experience in 13 intractable cases. RMD Open 2015;1:e000162.

10 Toussirot É, Martin A, Soubrier M, et al. Rapid and sustained response to tocilizumab in patients with polymyalgia rheumatica resistant or intolerant to glucocorticoids: a multicenter open-label study. J Rheumato/ 2016;43:249-51.

11 Leeb BF, Bird HA. A disease activity score for polymyalgia rheumatica. Ann Rheum Dis 2004;63:1279-83.

12 Leeb BF, Rintelen B, Sautner J, et al. The polymyalgia rheumatica activity score in daily use: proposal for a definition of remission. Arthritis Rheum 2007;57:810-15.

13 Binard $\mathrm{A}$, de Bandt $\mathrm{M}$, Berthelot JM, et al. Performance of the polymyalgia rheumatica activity score for diagnosing disease flares. Arthritis Rheum 2008;59:263-9.

14 Binard A, Lefebvre B, De Bandt $M$, et al. Validity of the polymyalgia rheumatica activity score in primary care practice. Ann Rheum Dis 2009;68:541-5.

15 Cleuziou C, Binard A, De Bandt M, et al. Contribution of the polymyalgia rheumatica activity score to glucocorticoid dosage adjustment in everyday practice. J Rheumatol 2012;39:310-13.

16 Chuang TY, Hunder GG, Ilstrup DM, et al. Polymyalgia rheumatica: a 10-year epidemiologic and clinical study. Ann Intern Med 1982;97:672-80.

17 Dasgupta B, Salvarani C, Schirmer M, et al. Developing classification criteria for polymyalgia rheumatica: comparison of views from an expert panel and wider survey. J Rheumatol 2008;35:270-7.

18 Dasgupta B, Cimmino MA, Kremers HM, et al. 2012 Provisional classification criteria for polymyalgia rheumatica: a European League Against Rheumatism/American College of Rheumatology collaborative initiative. Ann Rheum Dis 2012;71:484-92.

19 Carmona FD, Mackie SL, Martin JE, et al. A large-scale genetic analysis reveals a strong contribution of the HLA class II region to giant cell arteritis susceptibility. Am J Hum Genet 2015;96:565-80.

20 Dejaco C, Duftner C, Cimmino MA, et al. Definition of remission and relapse in polymyalgia rheumatica: data from a literature search compared with a Delphi-based expert consensus. Ann Rheum Dis 2011;70:447-53. 